\title{
An Electromagnetic Model for the Calculation of Tower Surge Impedance Based on Thin Wire Approximation
}

\author{
Bamdad Salarieh, H. M. Jeewantha De Silva, Aniruddha M. Gole, Fellow, IEEE, Akihiro \\ Ametani, Life Fellow, IEEE, and Behzad Kordi, Senior Member, IEEE
}

\begin{abstract}
When lightning strikes a transmission line tower or shield wires, electromagnetic waves propagate through the tower back and forth, increasing the voltage across insulator strings. This can eventually lead to a back-flashover (BF), which may cause damage to equipment or costly power outages. To calculate the over-voltages and predict the probability of a $\mathrm{BF}$, an accurate model of the tower and its grounding system is needed in electromagnetic transient (EMT) type simulators. There are a number of theoretical models for the equivalent circuit of a transmission tower. However, they either are not accurate enough or they are derived for a certain type of transmission tower, which limits their applicability. Numerical electromagnetic analyses have less simplifications compared to the theoretical solutions and are by far less expensive than field measurements. They also have the flexibility to analyse any type of tower. In this paper, the direct method for the measurement of tower impedance is implemented by NEC4 and applied to a $400-\mathrm{kV}$ double circuit tower with all its details. The process of obtaining the wire network of the tower used in this paper is completely automated and it can be applied to any other type of transmission tower. The results of the numerical simulations are compared to those obtained with existing tower models. The developed model in this paper is capable of considering all the details of the tower and including the finite resistance of the ground and grounding electrodes.
\end{abstract}

Index Terms-Electromagnetic analysis, power system transients, numerical analysis, surge protection.

\section{INTRODUCTION AND BACKGROUND}

$\mathrm{C}$ ALCULATION of overvoltages in power transmission lines struck by lightning has been the subject of much research in the past decades. The accurate representation of the transmission line tower and its grounding system is an essential part of studying the transient behavior of the power system. The advances made in the protection mechanisms require a greater precision in the calculations concerning the transmission line tower.

The approaches for modeling transmission line towers can be divided into three categories: (i) theoretical, (ii) numerical, and (iii) experimental that are performed/implemented either

B. Salarieh, and H. M. J. De Silva are with Manitoba Hydro International, Winnipeg, MB R3P 1A3, Canada (e-mail: salarieb@mhi.ca; jeewantha@mhi.ca).

A. M. Gole, A. Ametani, and B. Kordi are with the Department of Electrical and Computer Engineering, University of Manitoba, Winnipeg, MB R3T 5V6, Canada (e-mail: Aniruddha.Gole@umanitoba.ca; aametani@mail.doshisha.ac.jp; behzad.kordi@umanitoba.ca).

Manuscript received xxxx. xx, xxxx; revised xxxx. xx, xxxx. in the time [1]-[14] or frequency domains [15]-[17]. The numerical analyses are based on a) the Method of Moments (MoM) [17]-[19], b) Finite Element Method (FEM) [20], [21], c) Hybrid Electromagnetic Model (HEM) [22], or d) Finite Different Time Domain (FDTD) method [23]-[28]. Experimental measurements have been performed on full scale towers [28]-[32] or scaled towers [4], [11], [29], [33], [34]. Regardless of the approach, the aim of such analysis is to either find an equivalent impedance or derive an equivalent electric circuit for the transmission line tower with the same response as the measured waveforms. In the theoretical approaches, it is not possible to consider all the tower details, such as its cross arms or bracings. Furthermore, the tower body is approximated by simple geometries such as a cylinder (e.g. [5]) or cone (e.g. [4]). There are only a few experimental studies on a limited number and types of in-service towers as such measurements require an outage and are quite costly. Due to the restrictions of the theoretical and experimental approaches, developing an automated process for the numerical analysis of transmission towers is receiving more attention in recent years.

Considering the computational electromagnetic (CEM) techniques, FEM, MoM and FDTD can be used to solve the full-wave Maxwell's equations [35]. The MoM is a numerical technique employed for the solution of integral equations, while FEM and FDTD are differential-equation based. As such, FEM and FDTD need to discretize the entire simulation space whereas the MoM will only require a discretization of the wire structure. This is an advantage of using MoM for the simulation of open-region problems, such as the simulation of transient behavior of transmission line towers in this paper, that provides an efficient technique. Hence, the MoM is used in this paper in the numerical simulations.

Following a thorough overview of the existing models for the transmission line towers and their underlying assumptions, a numerical method based on thin wire approximation of the tower is presented in this paper. The Numerical Electromagnetic Code (NEC4) is used to determine the surge impedance of a double circuit transmission line tower either above a perfect electric conductor (PEC) ground or with grounding electrodes buried in lossy ground. The developed model is verified by simulating cylinders of different heights and comparing the results with the measurements available in the literature. Counterpoise grounding electrodes of different lengths (from 5 to $20 \mathrm{~m}$ ) 
are considered in soil with resistivity of 100 and $1000 \Omega \mathrm{m}$. In contrast to the theoretical tower models, the proposed model is general and it can be applied to analyse the transient behavior of any type of transmission tower.

\section{Definition of Tower Surge Impedance}

There are three definitions for the time-domain surge impedance of a tower in the literature [36]. The transient surge impedance is a time-domain function and is defined as the ratio of the instantaneous values of the voltage at top of the tower $v(t)$ to the injected current to the tower $i(t)$ [9],

$$
z(t)=\frac{v(t)}{i(t)} .
$$

This definition only works for purely resistive circuits, where the voltage and current have the same waveshapes. The other definition of the surge impedance is by considering a step or ramp current injected into the tower and is given by [15]

$$
z(t)=\frac{v(t)}{\max [i(t)]} .
$$

The commonly-used definition is the ratio of the voltage peak to the current at the time of voltage peak [6] given by

$$
Z=\frac{\max [v(t)]}{I}
$$

where $I$ is the value of $i(t)$ when the voltage $v(t)$ is maximum. This definition of the surge impedance is not a function of time.

As will be shown in Section V-A, the above time-domain definitions of the surge impedance are dependent on the waveshape of the injected current [36]. In order to mitigate this issue and to define a more general impedance for the tower, the frequency-domain surge impedance given by

$$
Z(f)=\frac{V(f)}{I(f)}
$$

is used in this paper, where $I(f)$ is the injected current at the tower top and $V(f)$ is the voltage at the top of the tower. This definition depends only on the geometry and electromagnetic properties of the tower.

\section{An Overview of Tower Models}

The large number of existing models for transmission line towers [1]-[10], [16], [26], [27], [29], [30], [37]-[44] can be classified in three categories based on the underlying assumptions and the components used to represent the tower as follows.

1) Vertical Lossless Frequency-Independent Models: These types of models approximate the tower body, i.e. its main legs and cage, with a simple geometric shape such as a cylinder [3]-[9], [39], [42] or a cone [4], [6]. The characteristic impedance of the whole tower as a function of the height above ground is derived using basic electromagnetic field analysis. In some, the current that is injected to the tower is assumed to be of a specific shape, such as a ramp [6], [42], a double exponential [6], [38], or a rectangular wave shape [7], [9], that restricts the applicability of such tower models to other waveshapes. Furthermore, the effect of tower cross arms and bracings is neglected, and the criteria for the selection of the radius of the equivalent structure is not well established. Figure 1A shows a typical double circuit tower, which is considered in this paper, and Fig. 1B shows its representation by such models. Table I shows the surge impedance of the double-circuit tower calculated based on these models.

2) Multisection Lossless Transmission Line Models: In these models, similar to the previous, only the main body of the tower is considered, but it is divided into a number of lossless transmission lines, usually four, and the characteristic impedance of each part is derived by analysing the tower elements as a multiconductor system [1]-[3], [16]. Table II shows the value of the surge impedance in each section for a 4-story tower model as shown in Fig. 1C. In the model of Hara \& Yamamoto [3], the tower cross arms are also modeled by horizontal lossless transmission lines $\left(Z_{A i}\right)$, and the bracings are modeled by a surge impedance $\left(Z_{L i}=9 Z_{T i}\right)$ in parallel to the tower main body in each section, as shown in Fig. 1D.

3) Multistory Tower Models: As shown in Figs. 1E and 1F, these tower models divide the tower into four segments at the upper, middle, and lower phase arm positions. Each section consists of a lossless transmission line $Z_{T}$ in series with a parallel $R L$ circuit [26], [27], [29], [30], [43]-[45]. The

\begin{tabular}{|c|c|c|c|}
\hline No & Model & Expression & $Z_{T}(\Omega)$ \\
\hline 1 & Wagner \& Hileman [9] & $60 \ln \left(\sqrt{2} \frac{2 h}{r_{0}}\right)$ & 205 \\
\hline 2 & Jordan [6] & $60 \ln \left(\frac{h}{r_{1}}\right)-60$ & 129 \\
\hline 3 & $\begin{array}{c}\text { Sargent \& Darveniza } \\
{[6]}\end{array}$ & $60 \ln \left(\sqrt{2} \frac{2 h}{r_{3}}\right)-60$ & 195 \\
\hline 4 & $\begin{array}{c}\text { Sargent \& Darveniza } \\
{[6]}\end{array}$ & $60 \ln \left(\sqrt{2} \frac{\sqrt{h^{2}+r_{0}^{2}}}{r_{0}}\right)$ & 160 \\
\hline 5 & $\begin{array}{c}\text { Menemenlis \& Chun } \\
{[38]}\end{array}$ & $50+35 \sqrt{h}$ & 285 \\
\hline 6 & Chisholmet al. [4] & $60 \ln \left(\cot \left(\frac{\tan ^{-1}\left(\frac{r_{0}}{h}\right)}{2}\right)\right)$ & 184 \\
\hline 7 & Chisholmet al. [4] & $60 \ln \left(\cot \left(\frac{\tan ^{-1}\left(\frac{r_{0}}{h}\right)}{2}\right)\right)-60$ & 124 \\
\hline 8 & Chisholmet al. [5] & $60 \ln \left(\cot \left(\frac{\tan ^{-1}(T)}{2}\right)\right)$ & 190 \\
\hline 9 & Flash version 1.7 [39] & $60 \sqrt{\frac{\pi}{4}} \ln \left(\frac{1}{\sqrt{2}} \cot \left(\frac{\tan ^{-1}(T)}{2}\right)\right)$ & 150 \\
\hline 10 & Hara \& Yamamoto [3] & $60 \ln \left(\sqrt{2} \frac{2 h}{r_{0}}\right)-120$ & 167 \\
\hline 11 & $\begin{array}{l}\text { De conti [8], } \\
\text { Takahashi [7] }\end{array}$ & $60 \ln \left(\frac{4 h}{r_{0}}\right)-60$ & 166 \\
\hline 12 & IEEE WG [42] & $60 \ln \left(\frac{h}{r_{0}}\right)$ & 142 \\
\hline 13 & Takahashi [7] & $60\left[\ln \left(\sqrt{2} \frac{2 h}{r_{0}}\right)-1.54\right]$ & 112 \\
\hline
\end{tabular}

TABLE I

SURGE IMPEDANCE OF THE DOUBLE CIRCUIT TOWER CALCULATED BY LOSSLESS FREQUENCY-INDEPENDENT TOWER MODELS.

${ }^{1}$ The radius of the tower at its base, waist and top are $r_{0}, r_{1}, r_{2}$, respectively. $r_{3}$ is the radius of the cylinder approximating the tower.

${ }^{2}$ The height of the tower is $h$, height from base to waist is $h_{1}$ and height from waist to top is $h_{2}$.

${ }^{3} T=\left(r_{2} h_{2}+r_{1} h+r_{0} h_{1}\right) / h^{2}$. 


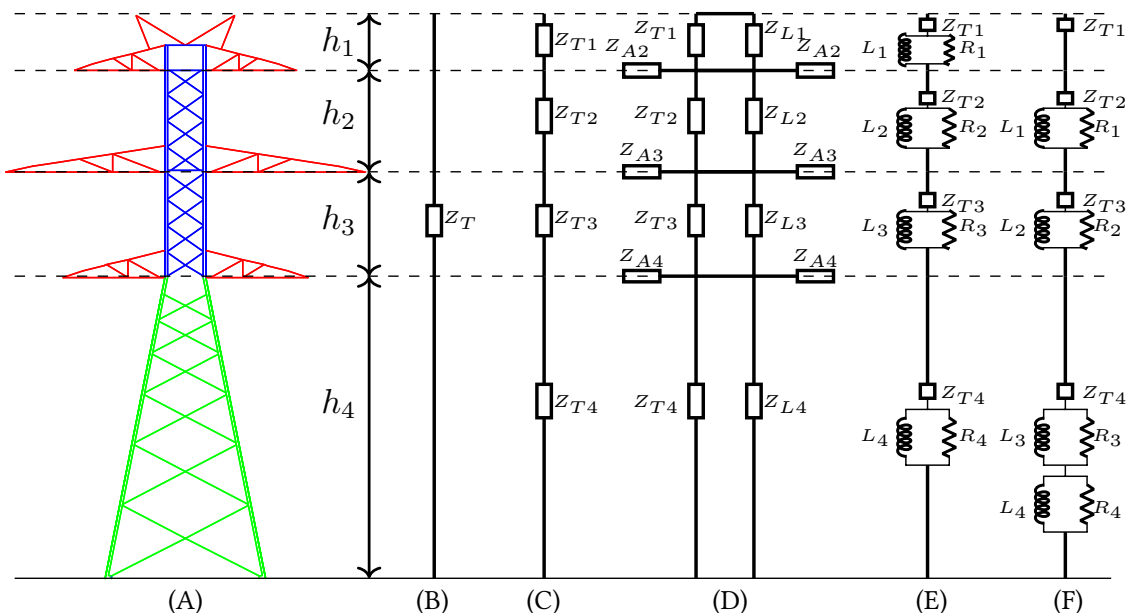

Fig. 1. (A) $400 \mathrm{kV}$ double circuit transmission line tower, and its equivalent circuits: (B) lossless frequency-independent equivalent circuit, (C) multisection lossless line, (D) the model of Hara \& Yamamoto [3] which considers the cross arms and bracings, (E) Multistory tower model, and (F) is the model of Baba [44].

TABLE II

SURGE IMPEDANCE OF THE DOUBLE CIRCUIT TOWER CALCULATED BY LOSSLESS TOWER MODELS (MULTI CONDUCTOR SYSTEM).

\begin{tabular}{|c|c|c|c|c|c|}
\hline No & Model & $Z_{T 1}(\Omega)$ & $Z_{T 2}(\Omega)$ & $Z_{T 3}(\Omega)$ & $Z_{T 4}(\Omega)$ \\
\hline 14 & Ametani [16] & 95 & 112 & 102 & 87 \\
\hline 15 & $\begin{array}{c}\text { Ametani simplified } \\
{[16]}\end{array}$ & 88 & 108 & 96 & 75 \\
& Gutierrez [2], [1] & 270 & 253 & 230 & 167 \\
\hline 16 & & 128 & 120 & 106 & 83 \\
& & $Z_{L 1}(\Omega)$ & $Z_{L 2}(\Omega)$ & $Z_{L 3}(\Omega)$ & $Z_{L 4}(\Omega)$ \\
\cline { 3 - 6 } 17 & Hara \& Yamamoto & 1152 & 1080 & 954 & 747 \\
& {$[3]$} & $Z_{A 1}(\Omega)$ & $Z_{A 2}(\Omega)$ & $Z_{A 3}(\Omega)$ & $Z_{A 4}(\Omega)$ \\
\cline { 2 - 5 } & & - & 305 & 282 & 257 \\
\hline
\end{tabular}

resistance represents the attenuation of traveling waves in the tower, and the inductance makes the resistance ineffective as time passes by and also adjusts the propagation velocity along the tower [30]. These models are derived based on the results of field measurements on actual towers and the values of the tower surge impedance and attenuation coefficients have to be determined by a trial and error process such that the response of the circuit representing the tower would be the same as the measured ones. There are limitation in extending the results of such models to other types of transmission towers [30]. Table III shows the values of tower parameters calculated based on these models, and the equivalent circuit of the tower is shown in Fig. 1E. In the model proposed by Ishii and Baba [44], two parallel $R L$ elements are considered in the lower tower section as shown in Fig. 1F.

\section{Verification of the Numerical Analysis}

To inspect the validity of a model for transient simulation of transmission line towers, field measurements on simple geometric shapes or real towers can be employed. Measurement of the tower surge impedance is performed in two ways: one is the direct method [11], [31], where a current pulse is injected into the tower top and the voltage between the tower top and a reference voltage measuring wire is measured using a voltage divider. The other method is the reflection method [46], where a steep-front traveling wave is injected into the tower top using a wire, and the reflected wave is observed to estimate the transient impedance of the tower. In this paper, the former method of measurement is implemented using numerical simulations, since the reflection method is only valid when evaluating the reflection of waves from adjacent towers [47]. Due to the complexity and cost of measurements on transmission line towers, the number of measurements are highly limited and restricted. Furthermore, the data of the tower and grounding system used for the measurement is not available in detail.

Measurements of the surge characteristics of cylinders with different heights and radii performed by Hara et al. [45] are employed to validate the accuracy and applicability of the proposed simulation model. The simulations are performed using Numerical Electromagnetic Code (NEC-4), which is based on the thin wire approximation and the numerical solution of integral equations by means of the Method of Moments (MoM) [48]. NEC is a well-known frequency-domain electromagnetic solver that employs the MoM [35]. In the measurements of [45], the electrodes are placed on a $12 \times 10 \mathrm{~m}^{2}$ iron plate as the ground as shown in Fig. 2. The current is applied to the top of the vertical conductor by a current lead extended horizontally $9 \mathrm{~m}$ away. The voltage is measured using a voltage probe in the gap between the top of the cylindrical conductor and a voltage reference wire, which is horizontally extended to the remote ground and it is perpendicular to the current lead wire to minimize the coupling effects. Both the current and voltage wires are attached vertically to the ground at their ends, using a matching resistance $\left(R_{c}\right)$ to avoid reflections.

The measurement performed on a $3-\mathrm{m}$ high cylinder with 
TABLE III

SURGE IMPEDANCE OF THE DOUBLE CIRCUIT TOWER CALCULATED BY MULTISTORY TOWER MODELS.

\begin{tabular}{|c|c|c|c|c|c|c|c|c|c|c|c|c|c|}
\hline No & Model & $Z_{T 1}(\Omega)$ & $Z_{T 2}(\Omega)$ & $Z_{T 3}(\Omega)$ & $Z_{T 4}(\Omega)$ & $R_{1}(\Omega)$ & $R_{2}(\Omega)$ & $R_{3}(\Omega)$ & $R_{4}(\Omega)$ & $L_{1}(\mu H)$ & $L_{2}(\mu H)$ & $L_{3}(\mu H)$ & $L_{4}(\mu H)$ \\
\hline 18 & Ishii [30] & 220 & 220 & 220 & 150 & 8.32 & 20.37 & 20.37 & 33.47 & 3.49 & 8.53 & 8.53 & 14.01 \\
\hline 19 & Yamada [29] & 120 & 120 & 120 & 120 & 9.30 & 16.45 & 17.06 & 42.80 & 2.79 & 4.94 & 5.13 & 12.86 \\
\hline 20 & Motoyama [43] & 120 & 120 & 120 & 120 & 5.83 & 11.70 & 9.32 & 26.80 & 2.31 & 4.61 & 3.69 & 10.60 \\
\hline 21 & Baba [44] & 200 & 200 & 180 & 150 & 20 & 30 & 25 & 25 & 6 & 9 & 15 & 1.5 \\
\hline 22 & $\begin{array}{l}\text { Hashimoto [27] } \\
\end{array}$ & 195 & 182 & 149 & 121 & 13.30 & 32.50 & 28.10 & 76.10 & 7.42 & 18.10 & 15.70 & 52.7 \\
\hline
\end{tabular}

a radius of $2.5 \mathrm{~mm}$ is considered for the numerical analysis in NEC4. A $10 \mathrm{k} \Omega$ resistance is inserted between the top of the electrode and end of the voltage reference wire. The voltage is evaluated by calculating the current flowing through this resistor. It shown that the value of the voltage-measuring probe has no significant impact on the measurement if its internal capacitance is less that a certain limit [49]. Finally, the inverse Fourier transform is used to obtain the time domain voltage and current.

The voltage waveform shown in Fig. 3, adopted from [45], is used as the input to the system. Figure 3 shows the measured and simulated currents injected at the top of the cylinder that shows the accuracy of simulation results, in terms of both the waveshape and magnitude. The measured current initially rises for $5 \mathrm{~ns}$ and remains almost constant till $t=20 \mathrm{~ns}$ that is when the reflected wave from the ground reaches the top of the cylinder. The approach in the paper has been partially validated by comparison with simple geometric structures. However, complete validation will require comparison with field test results on transmission line towers. This is relegated to forthcoming papers.

\section{Results And Discussions}

In this section, firstly, the simulation results are presented for vertical cylinders and the double-circuit tower (shown in Fig. 9) on a PEC ground. The dependence of time-domain surge impedance and the effect of tower elements are investigated. Finally, the effect of lossy ground on the simulated results is presented and discussed.

\section{A. Dependence of Time-Domain Surge Impedance on the Excitation Waveshape}

In this section, we also employ the measurements of Hara et al. [45] are considered to show the dependence of time-domain impedance definitions on the waveshape of the excitation. In [45], the so-called maximum surge impedance,

Pulse generator

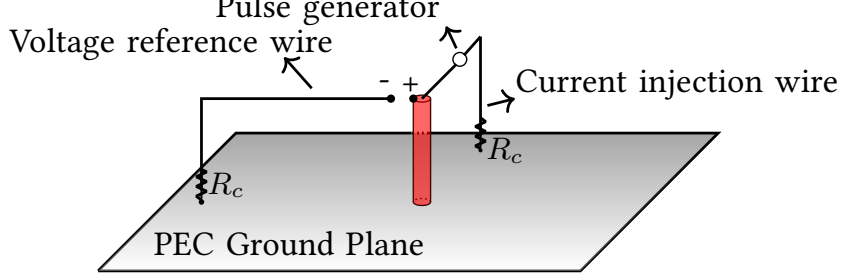

Fig. 2. Setup for the measurement of surge characteristics of a vertical cylinder by direct method as performed by Hara et al. in [45].

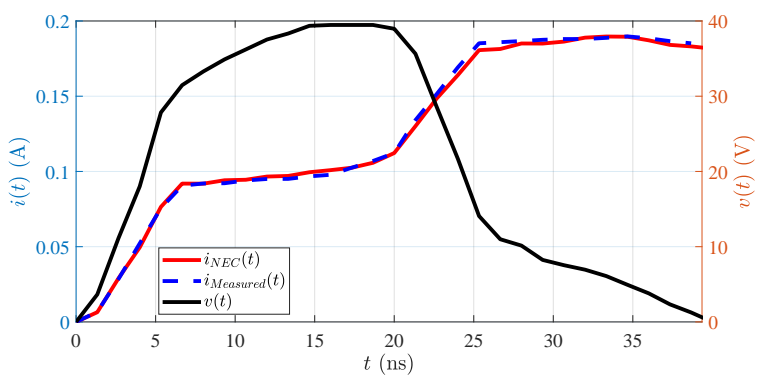

Fig. 3. Voltage at the top of the cylinder with reference to remote ground (right axis) and measured and simulated current (left axis) injected at the top of a 3-m cylinder on a PEC ground.

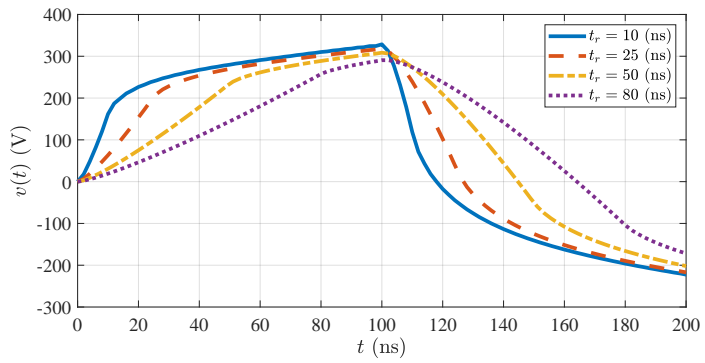

Fig. 4. Simulated voltage at the top of a 15 -m vertical cylinder in response to pulse currents of $1 \mathrm{~A}$ in magnitude and rise time of $t_{r}$ injected at the tower top.

as given in (3), was used. A step input current with a rise time of $5 \mathrm{~ns}$ is applied to the cylinder (see Fig. 2) and the surge impedance is calculated at $t_{0}=2 h / c$, where $h$ is the height of the cylinder and $c$ is the speed of light. For the case of a cylinder with a height of $15 \mathrm{~m}$ and a radius of $25.4 \mathrm{~mm}$, the measured surge impedance is $320 \Omega$ [45]. The same cylinder is simulated in NEC4 in the frequency range of 0.1 to $250 \mathrm{MHz}$. The length of the current and voltage leads are $115 \mathrm{~m}$, so that the reflected waves do not affect the results until $760 \mathrm{~ns}$. Step currents with various rise times from $t_{r}=10$ to $80 \mathrm{~ns}$ are injected into the top of the cylinder. The values of $t_{r}$ are less than the round-trip travel time of the wave along the cylinder, which is equal to $t_{0}=100 \mathrm{~ns}$. As a result, the effect of grounding system appears after the peak of the voltage waveform. The voltage at the top of the cylinder relative to the voltage reference wire is shown in Fig 4. The rise time of the voltage waveform is almost equal to the rise time of the injected current and there is a reflection from the ground at $t_{0}=100 \mathrm{~ns}$. Calculating the surge impedance of the tower for the considered excitations 
using (3), $Z$ varies from 324.6 to $293 \Omega$, which is equal to a variation of $9.7 \%$, when the rise time is increased from 10 to 80 ns. Considering a double exponential excitation waveshape, which is commonly used in lightning studies, the surge impedance defined by (3) decreases from $316.8 \Omega$ for a a rise time of $T_{1}=10 \mu \mathrm{s}$ to $232.5 \Omega$ for a double exponential waveform with a rise time of $T_{1}=200 \mu \mathrm{s}$.

\section{B. Effect of Tower Elements}

In order to simulate a structure using NEC a wire-grid representation of the structure has to be created as NEC has no ability to import arbitrary 3D geometries. It needs the start and end points of the segments of the wire grid that comprise the thin-wire model representation of the structure. Using the CAD file of the tower geometry, its a prohibitively laborious process to obtain the coordinates manually. In this paper, an automated process is developed that uses the double circuit tower CAD file (in 'step' format) to generate the thin-wire model of the tower (as shown in Fig. A.1). This provides a detailed model of the tower for the numerical simulations by NEC4. It also enables the sensitivity study with regards to the level of detail required for an accurate simulation.

Generally, a typical transmission line tower consists of a main body (green in Fig. 1A), a cage (blue), cross arms (red), and slant and horizontal elements (also blue). The double circuit tower is simulated in NEC4 in the frequency range of 0.1 to $240 \mathrm{MHz}$ with four level of details. Firstly, only the main legs with a height of $24.01 \mathrm{~m}$ are considered (Case 1). Next, the tower cage is added to the main legs, making the tower height equal to $42.51 \mathrm{~m}$ (Case 2). In Case 3, the cross arms are added to the geometry, and finally, the shield wire cross arms, bracing, and horizontal elements are taken into account in Case 4. The simulation configuration is the same as that shown in Fig. 2 and the horizontal extension of the leads is $200 \mathrm{~m}$ far from the top of the geometry. In the simulations performed in this section, to achieve a desirable resolution in the frequency domain, 800 frequency points are used.

Two ramp currents with a magnitude of $1 \mathrm{~A}$ and rise times of $t_{r}=50$ and $150 \mathrm{~ns}$ are used as the current waveform injected into the top of the structure through the current lead wire. Assuming that the waves propagate through the tower structure at the speed of light, the travel time $t_{0}=2 \mathrm{~h} / \mathrm{c}$ in Cases 1, 2, and 3 should be 160, 283 and 300 ns, respectively. The voltage at the top of the structure is shown in Fig. 5 for $t_{r}=50 \mathrm{~ns}$. The surge impedance of each structure calculated using (3) at $t_{0}=2 h / c$ and also the apparent propagation speed $\left(v_{0}\right)$, that is when we consider a straight vertical conductor, relative to the speed of light $(c)$ are given in Table IV. It can be seen that the inclusion of the cross arms in the model decreases the tower surge impedance by $16.1 \%$ in the case of fast-rising currents $\left(t_{r}=50 \mathrm{~ns}\right)$ and $10.9 \%$ in the case of a excitation with a rise time of $t_{r}=150 \mathrm{~ns}$. This is in agreement with previous measurements that considered the tower cross arms as capacitively-loaded stubs in parallel with the tower body [4]. Figure 6 shows the voltage at the tower of Case 3 when the rise time of the excitation ramp

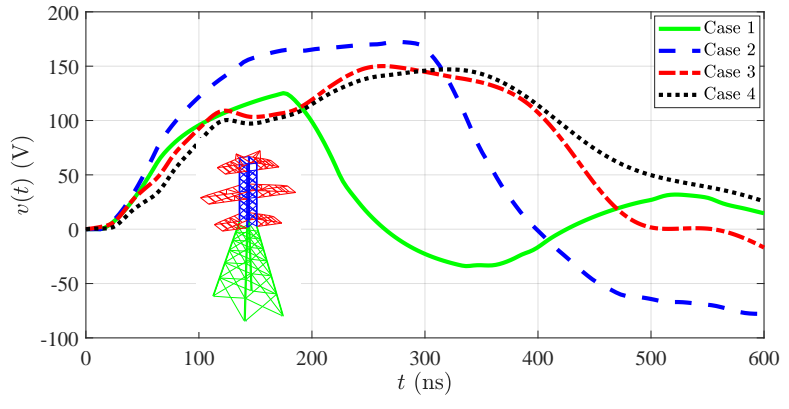

Fig. 5. The effect of tower elements on the voltage at the top of the structure for a ramp current with a rise time of $t_{r}=50 \mathrm{~ns}$ injected into the structure.

TABLE IV

SURGE IMPEDANCE AND WAVE PROPAGATION SPEED OF THE DOUBLE CIRCUIT TOWER WHEN DIFFERENT LEVEL OF DETAILS FOR THE TOWER ARE CONSIDERED.

\begin{tabular}{cccc}
\hline Geometry & $Z_{50}(\Omega)$ & $Z_{150}(\Omega)$ & $v_{0} / c(\%)$ \\
\hline Case 1 & 106.3 & 103 & 90.8 \\
\hline Case 2 & 172.4 & 164.1 & 91 \\
\hline Case 3 & 153.7 & 136.5 & 87 \\
\hline Case 4 & 145.9 & 137.2 & 84 \\
\hline
\end{tabular}

current is $1 \mathrm{~ns}$. The reflections observed in the waveshape show a negative reflection coefficient from the end of the cross arms [4]. The travel time of the upper cross arm, considering a propagation speed equal to the speed of light is $38.67 \mathrm{~ns}$, which is in agreement with the reflections observed in this figure. However, such reflections will have no considerable effect in the case of currents with higher rise times. This shows that the extent of which each tower element affects the tower surge impedance depends on the excitation waveshape. The tower in Cases 3 and 4 have almost a similar surge impedance for all waveshapes. This can be justified by considering the opposing effects that adding the shield wire cross arms and tower bracing have on the impedance of the tower [17]. In all four cases, the apparent travel speed is lower than $91 \%$ of the speed of the light due to the presence of different tower elements that increase the propagation path of the waves.

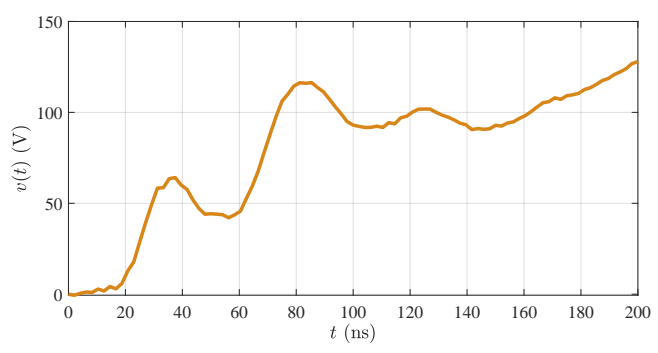

Fig. 6. Negative reflections from the end of tower cross arms when a fast rising current is applied to the tower top in case 3. 


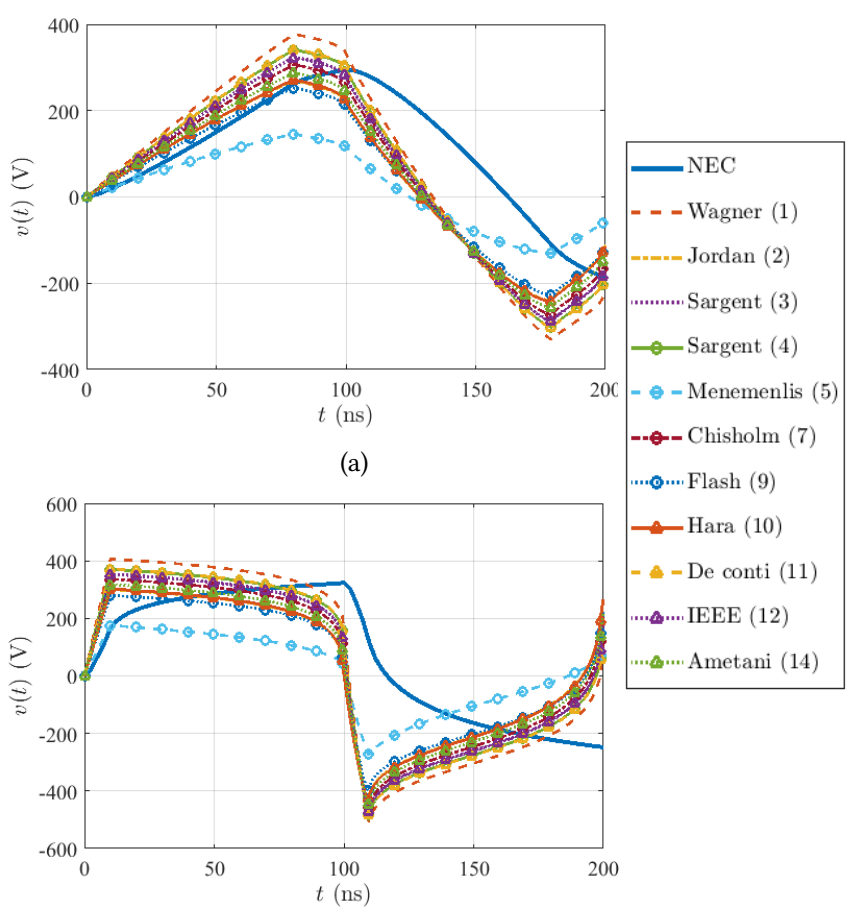

(b)

Fig. 7. Comparison of the voltage at the top of a $15-\mathrm{m}$ cylinder obtained by numerical analysis and the models of Tables I and II. The excitation current is a ramp with a rise time of (a) $t_{r}=80 \mathrm{~ns}$ and (b) $t_{r}=10 \mathrm{~ns}$.

\section{Comparison of Theoretical and Simulation Results}

In this section, to assess the accuracy of different tower models on the prediction of tower top voltage, they are compared with the numerical results for the case of the vertical cylinders with heights of 15,45 , and $90 \mathrm{~m}$. They are also compared with the numerical results for the case of the double circuit tower over a lossy ground.

\section{A. Vertical Cylinders}

Figures $7 \mathrm{a}$ and $7 \mathrm{~b}$ show the voltage at the top of the cylinder for the case of a vertical cylinder with a height of $15 \mathrm{~m}$ on a PEC ground when injected with currents with rise times of $t_{r}=80$ and $t_{r}=10 \mathrm{~ns}$, respectively. This figure presents a comparison of 11 of existing models with that obtained using NEC4. The predicted waveform of the theoretical solutions is closer to that obtained by NEC4 when the rise time of the injected current is 80 ns (see Fig. 7a). Whereas, in the case of a rise time of $10 \mathrm{~ns}$, the calculated waveshape using the theoretical models are step-like and are different from the simulated voltage in NEC4, which shows a slower rise-time and decay. This is due to the fact that the early-time electromagnetic fields around the cylinder is different from TEM but the theoretical models assume the electromagnetic fields are always TEM.

\section{B. Double Circuit Tower}

Figure 8a shows the voltage at the top of the double circuit tower obtained using NEC and theoretical approaches 4 and

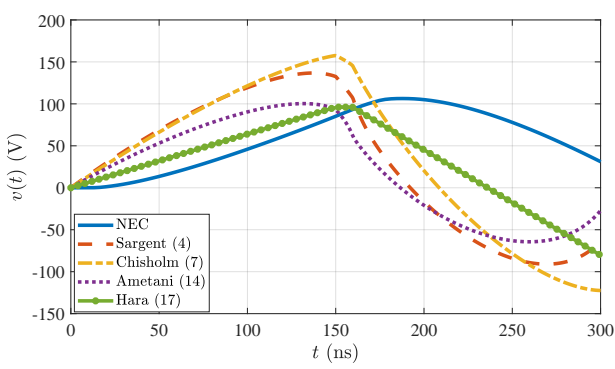

(a)

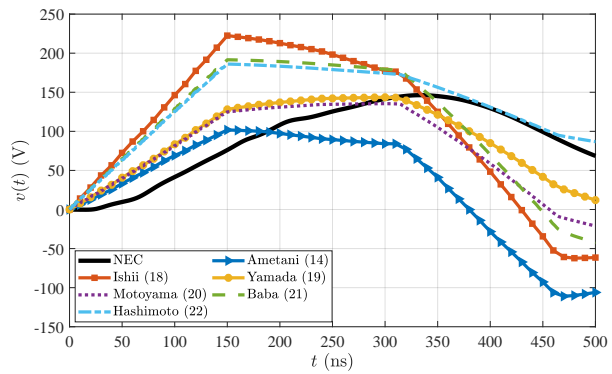

(b)

Fig. 8. The voltage at the top of the structure of Case 1 (a) and Case 4 (b) in response to a ramp excitation of rise time $t_{r}=150 \mathrm{~ns}$.

7 from Table I and 14 and 17 from Table II, for which we used the method of characteristics of partial differential equations theory [50]. A rise time of $t_{r}=150 \mathrm{~ns}$ is considered such that the rise time is less than the travel time. In the theoretical approaches, the wave propagation speed is assumed to be the speed of light, however, in the numerical result shown in Fig. 8a, the apparent wave speed is equal to $87 \%$ of the speed of light. This is in agreement with measurements which suggest $80 \%$ [6], $71 \%, 76 \%, 81 \%$ and $89 \%$ of the speed of the light [31]. This justifies why the zero crossing of the NEC result is at a later time in comparison with the theoretical results. The multiconductor model of Ametani [16] and the model of Hara \& Yamamoto [3] show the closest values of the surge impedance ( relative difference of $5.3 \%$ and $6.8 \%$ ).

Now, let's consider a model of the double-circuit tower with all its details with the same current injected to the top of the tower. The multistory models of Table III are compared with the numerical analysis in Fig. 8b. Regarding the voltage peak, the closest predicted values are by the models of Yamada [29] (error of 2.8\%) and Motoyama (error of $8.4 \%$ ) [43]. Considering the waveshape of the voltage, the models of Yamada and Motoyama are closer than the others ones to the one predicted by NEC. However, the model of Hashimoto [27] shows a closer decaying part than the other models. As stated in [27], this is due to the modification in the derivation of this model in order to reproduce the gradual decay of the measured voltages. All of the multistory models of Table III require "tuning" based on measured waveform from a specific tower structure, whereas our approach based on numerical simulation solely requires the geometrical information of the tower. For example, the model of Ishii which has a large overestimation of the voltage, was derived for Japanese 


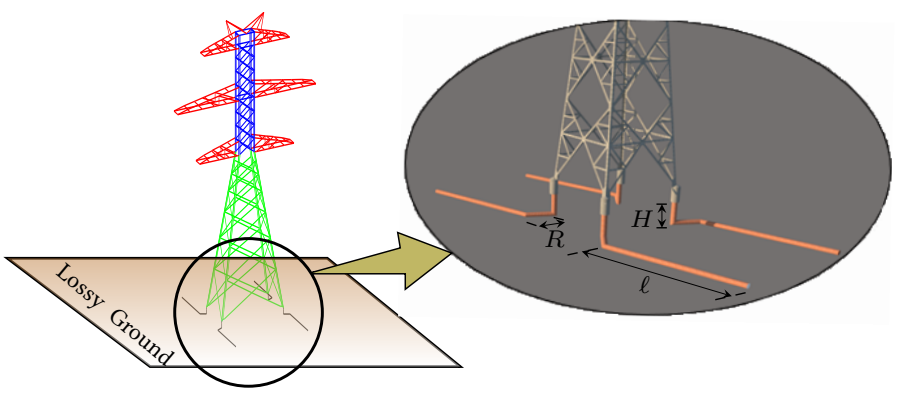

Fig. 9. The wire diagram of the double circuit tower generated by an automated procedure to be used in numerical simulations by NEC4. Sections of the tower, identified by different colors, and counterpoise grounding electrodes buried in lossy ground are shown.

$500 \mathrm{kV}$ [30] and UHV towers [29] that are taller (62.8 and $140.5 \mathrm{~m}$ ) than the typical double circuit towers like the one considered in this paper $(45.1 \mathrm{~m})$. The results shown in this section, demonstrate the multistory models of Table III have limited applicability.

\section{EfFect of Grounding System}

In the previous sections and most previous studies (e.g. [3], [4], [10]), the ground was assumed to be a Perfect Electric Conductor (PEC). However, in reality the conductivity of ground is finite. In this section, we consider a lossy ground where counterpoise grounding electrodes, $\ell=1,2,5,10$ and $20 \mathrm{~m}$ in length, are considered as the grounding system of the tower (see Fig. 9). The burial depth of the electrode is assumed to be $H=1 \mathrm{~m}$, with an opening length of $R=1 \mathrm{~m}$, and an optimized opening angle of $45^{\circ}$ [21]. Two soil resistivities of 100 and $1000 \Omega \mathrm{m}$ are considered. In the case of tower with all its details and grounding electrodes, the number of segments being analyzed in NEC4 is 7,654. A single-frequency simulation was completed in about 10 minutes on an Intel-Xeon, 3.1-GHz desktop computer.

Fig. 10a shows the simulated and theoretical voltage at the top of the tower when counterpoise grounding electrodes of $20 \mathrm{~m}$ in length buried in soil with a resistivity of $100 \Omega \mathrm{m}$ are considered. To obtain the response of theoretical tower models, first an electromagnetic simulation is performed on counterpoise grounding electrodes using the model presented in [51], to obtain their low frequency resistance. The obtained values agree well with the analytical formula provided in IEEE Std. 1243 [39]. This resistance is added to the tower models and the simulation is performed in PSCAD/EMTDC. The injected current is a $2 / 50 \mu s$ double exponential with a peak of $1 \mathrm{~A}$, and a shunt internal resistance of $5 \mathrm{k} \Omega$ [52] is considered to have the same condition as the numerical simulation. The most noticeable difference between an ideal and lossy ground is the difference in the peak of the voltages predicted by theories that is less in the case of a lossy ground but still considerable. Considering the NEC results, the models of Baba [18] and Yamada [29] produce the closest results considering both the peak of the voltage and its waveshape. The difference in the peak of the voltage is $2.5 \%$ and $5.6 \%$, respectively. Assuming a soil resistivity of

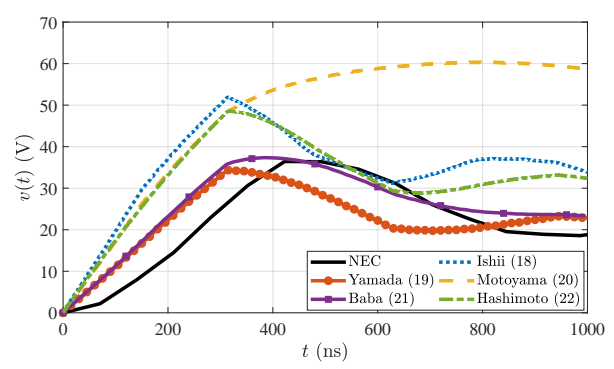

(a)

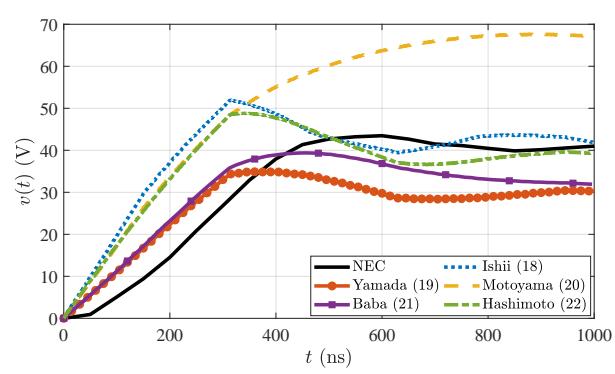

(b)

Fig. 10. The simulated and theoretical voltage at the top of the double circuit tower considering counterpoise grounding electrodes $(20 \mathrm{~m})$ in a soil with resistivity of (a) $\rho=100 \Omega / \mathrm{m}$ and (b) $\rho=1000 \Omega / \mathrm{m}$ and in response to double exponential current of $2 / 50 \mu$ s with a magnitude of $1 \mathrm{~A}$.

$1000 \Omega \mathrm{m}$, the same tower models as above generate the closest results to those generated by NEC (see Fig. 10b). However, the difference $(9.41 \%$ for Baba [18] and $20.45 \%$ for Yamada [29]) is higher as the resistivity of the soil is increased. In general, the theoretical tower models are a fast way to have an estimation of the developed over-voltages on a transmission tower, but they are not accurate for all tower models and the value of circuit elements need to be tuned for every topology of the tower using field measurements. For instance, the model proposed in [30] is most valid for the tested $500 \mathrm{kV}$ tower, with a height of $62.8 \mathrm{~m}$. Furthermore, the effect of excitation waveshape on the accuracy of predicted overvoltages is another challenge for the theoretical tower models. In field measurements, the transient voltages/currents are measured in the time domain by applying an impulse voltage waveform. So, the measured responses are dependent on the applied voltage waveform, as shown in this paper. Whether to use the theoretical tower models or the proposed simulation model in lightning studies, depends on the intended balance between the accuracy and simplicity. To gain higher accuracy, the numerical methods can be useful but they require more computational resources. Among the numerical techniques, the MoM is less computationally expensive. Moreover, as this is not a repetitive procedure in the transmission system analysis, a few hours spent on a detailed accurate design is not a critical issue.

\section{Conclusions}

In this paper, a detailed wire-model of a typical $400 \mathrm{kV}$ double-circuit tower with a height of $45.1 \mathrm{~m}$ was generated 
using an automated process that employs the CAD drawing of the tower. The wire model was then used in NEC4 to calculate the transient tower-top voltage considering the finite conductivity of the ground and the grounding electrodes. It was shown that the definition of tower surge impedance based on time domain voltage and current has a main disadvantage of being dependent on the excitation waveshape and rise time. Following a review of existing transmission tower models, they were compared with the results of NEC4 for the case of a simple cylinder and the $400 \mathrm{kV}$ double-circuit tower. Regarding the peak of the tower-top voltage, the theoretical models could provide close predictions to that of NEC4. Considering the voltage waveshape, theoretical models were not able to generate results close to those determined by NEC4 in the case of fast-front currents, because the initial electromagnetic field around the cylinder is not TEM. In the case of the double-circuit tower on a PEC ground, the models of Yamada [29] (difference of -2.8\%) and Motoyama [43] (difference of $-8.4 \%$ ) had the closest similarity to NEC4 results with regards to the calculated voltage peak. The proposed thin-wire model is capable of considering the effect of the finite conductivity of the ground. In order to compare this model for the case of a lossy ground, a grounding resistance was added to the theoretical models. The models of Baba [18] (difference of $+2.5 \%$ ) and Yamada [29] (difference of $-5.6 \%$ ) provide closer peak values to that of NEC4, although the error can not be considered as negligible when $\rho=1000 \Omega \mathrm{m}$ (the error is -9.41 and $-20.45 \%$, respectively). The existing models of transmission towers were derived based on either electromagnetic field analysis on a simplified model of the tower (approximated by a cone or cylinder), or by a trial-and-error process to find the resistance and inductance values of the circuit such that they produce similar waveform as the measurements on a certain type of tower. The multistory model provides reliable results for that specific type of tower. However, the circuit values, the surge impedance, the attenuation constants and velocities should be tuned to provide accurate results for other type of towers. The process of such tuning is not well established.

Unlike the theoretical tower models, the proposed process in this paper has the advantage of only needing the geometry of the tower as the input and it can be applied to arbitrary tower geometries. Moreover, the simulations are performed in the frequency domain by applying a variable-frequency sinusoidal voltage and the calculated result is not dependent on the applied voltage waveform. The proposed model could be further verified with the measurement results on real transmission line towers and be applied to analyze the transient behavior of any other type of transmission towers. This way, it would be possible to examine the generality of the results obtained in this paper in regard to other types of towers and reach a more general conclusion about the accuracy and limitation of the theoretical tower models.

\section{APPENDIX}

The dimensions of the considered double-circuit tower are given in Fig. A.1, and the electrical characteristics are
TABLE $\mathrm{V}$

ELECTRICAL CHARACTERISTICS OF THE TRANSMISSION LINE CONSIDERED IN THIS PAPER [53].

\begin{tabular}{|c|c|c|c|c|c|}
\hline $\begin{array}{c}\text { Operating } \\
\text { voltage } \\
(\mathrm{kV})\end{array}$ & $\begin{array}{c}\text { Conductor } \\
\text { type }\end{array}$ & $\begin{array}{c}\text { Conductor } \\
\text { diameter } \\
(\mathrm{mm})\end{array}$ & $\begin{array}{c}\text { OHGW } \\
\text { type }\end{array}$ & $\begin{array}{c}\text { OHGW } \\
\text { diameter } \\
(\mathrm{m})\end{array}$ & $\begin{array}{c}\text { Shielding } \\
\text { angle } \\
(\mathrm{deg})\end{array}$ \\
\hline 400 & $\begin{array}{c}\text { ACSR } \\
\text { Cardinal }\end{array}$ & 30.42 & $\begin{array}{c}\text { Glv } \\
\text { steel }\end{array}$ & 12.60 & 19.2 \\
\hline
\end{tabular}

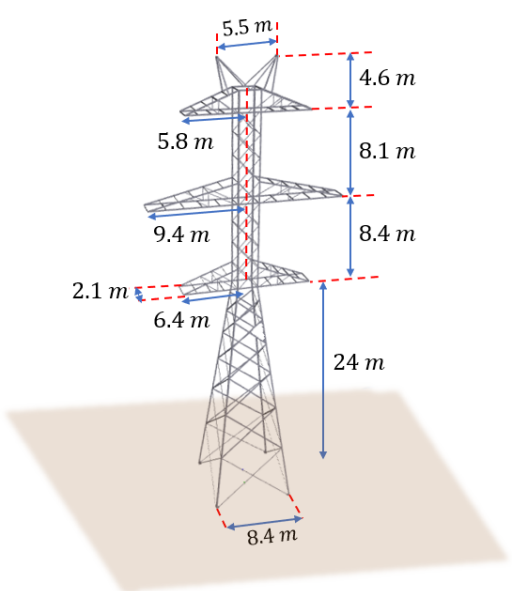

Fig. A.1. Geometry of the $400 \mathrm{kV}$ double-circuit transmission line tower employed in this paper.

provided in Table $\mathrm{V}$ (conductors and overhead ground wires (OHGW) are not considered in the simulations of this paper).

\section{REFERENCES}

[1] R. J. Gutiérrez, P. Moreno, L. Guardado, and J. L. Naredo, "Comparison of transmission tower models for evaluating lightning performance," 2003 IEEE Bologna PowerTech - Conf. Proc., vol. 4, pp. 339-344, 2003.

[2] J. A. Gutiérrez, R. P. Moreno, J. L. Naredo, J. L. Bermúdez, M. Paolone, C. A. Nucci, and F. Rachidi, "Nonuniform transmission tower model for lightning transient studies," IEEE Trans. Power Deli., vol. 19, no. 2, pp. 490-496, 2004.

[3] T. Hara and O. Yamamoto, "Modeling of a transmission tower for lightning-surge analysis," IEE Proceedings - Gen. Trans. Dist., vol. 143 , no. 3, p. 283, 1996.

[4] W. A. Chisholm, Y. L. Chow, and K. D. Srivastava, "Lightning surge response of transmission towers," IEEE Trans. Power App. Syst., vol. PAS-102, no. 9, pp. 3232-3242, 1983.

[5] W. A. Chisholm and Y. L. Chow, "Travel time of transmission towers," IEEE Trans. Power App. Syst., vol. PAS-104, no. 10, pp. 2922-2928, 1985.

[6] M. A. Sargent and M. Darveniza, "Tower Surge Impedance," IEEE Trans. Power App. Syst., vol. PAS-88, no. 5, pp. 680-687, 1969.

[7] H. Takahashi, "Confirmation of the error of Jordanfis formula on tower surge impedance," The fournal of the Inst. Elect. Eng. Japan, vol. 114-B, pp. 112-113, 1994.

[8] A. De Conti, S. Visacro, A. Soares, and M. A. O. Schroeder, "Revision, extension, and validation of Jordan's formula to calculate the surge impedance of vertical conductors," IEEE Trans. Electromagn. Compat., vol. 48, no. 3, pp. 530-536, 2006.

[9] C. F. Wagner and A. R. Hileman, "A New Approach to the Calculation of the Lightning Performance of Transmission Lines III-A Simplified Method: Stroke to Tower," Trans. of the American Inst. Elect. Eng. Part III: Power App. Syst., vol. 79, no. 16, pp. 589-603, 1960.

[10] M. O. Goni and A. Ametani, "Analysis and estimation of surge impedance of tower," Applied Computational Electromagn. Society, vol. 24 , no. 1, pp. 72-78, 2009. 
[11] F. A. Fisher, J. G. Anderson, and J. H. Hagenguth, "Determination of lightning response of transmission lines by means of geometrical models," Trans. of the American Inst. of Elect. Eng. Part III: Power App. and Syst., vol. 78, no. 4, pp. 1725-1734, 1959.

[12] M. T. Correia De Barros and M. E. Almeida, "Computation of electromagnetic transients on nonuniform transmission lines," IEEE Trans. Power Del., vol. 11, no. 2, pp. 1082-1087, 1996.

[13] H. Motoyama and H. Matsubara, "Analytical and experimental study on surge response of transmission tower," IEEE Trans. Power Del., vol. 15, no. 2, pp. 812-819, 2000.

[14] F. Rachidi, W. Janischewskyj, A. Hussein, C. Nucci, S. Guerrieri, B. Kordi, and J.-S. Chang, "Current and electromagnetic field associated with lightning-return strokes to tall towers," IEEE Trans. Electromagn. Compat., vol. 43, no. 3, 2001.

[15] F. P. Dawalibi, W. Ruan, S. Fortin, J. Ma, and W. K. Daily, "Computation of power line structure surge impedances using the electromagnetic field method," Proc. IEEE/Power Eng. Soc. Transm. Dist. Conf, vol. 2, pp. 663-668, 2001.

[16] A. Ametani, "Frequency-dependent impedance of vertical conductors and a multiconductor tower model," IEE Proceedings - Gen. Trans. Dist., vol. 141, no. 4, p. 339, 2002.

[17] Y. Baba and M. Ishii, "Numerical electromagnetic field analysis of tower surge response," IEEE Trans. Power Del., vol. 15, no. 3, pp. 1010-1015, 2000.

[18] Y. Baba and I. Masaru, "Tower Models for Fast-Front lightning currents," IEE Japan, vol. 120-B, no. 1, pp. 18-23, 2000.

[19] M. S. Yusuf, M. Ahmad, M. A. Rashid, and M. O. Goni, "Analysis of lightning surge characteristics on transmission tower," Engineering Letters, vol. 23, no. 1, pp. 29-39, 2015.

[20] P. C. A. Mota, M. L. R. Chaves, and J. R. Camacho, "Power Line Tower Lightning Surge Impedance Computation , a Comparison of Analytical and Finite Element Methods ." 2012 Int. Conf. on Renewable Energies and Power Quality, ICREPQ'12, no. March 2012, 2012.

[21] R. J. Anderson De Araujo, S. Kurokawa, C. M. D. Seixas, and B. Kordi, "Lightning-induced surge in transmission towers calculated using full-wave electromagnetic analysis and the method of moments," 2018 13th IEEE Int. Conf. Industry Applic., INDUSCON 2018 - Proc., pp. 943-948, 2019.

[22] A. Soares, M. A. O. Schroeder, and S. Visacro, "Transient voltages in transmission lines caused by direct lightning strikes," IEEE Trans. on Power Del., vol. 20, no. 2 II, pp. 1447-1452, 2005.

[23] T. H. Thang, Y. Baba, N. Nagaoka, A. Ametani, N. Itamoto, and V. A. Rakov, "FDTD simulation of insulator voltages at a lightning-struck tower considering ground-wire corona," IEEE Trans. Power Del, vol. 28, no. 3, pp. 1635-1642, 2013.

[24] J. Takami, T. Tsuboi, K. Yamamoto, and S. Okabe, "Lightning Surge Response of a Double-Circuit Transmission Tower with Incoming Lines to a Substation through FDTD Simulation," IEEE Trans. Dielectr. Electr. Insul., pp. 96-104, 2013.

[25] T. Noda, A. Tatematsu, and S. Yokoyama, "Improvements of an FDTD-based surge simulation code and its application to the lightning overvoltage calculation of a transmission tower," Electric Power Systems Research, vol. 77, pp. 1495-1500, 2007.

[26] T. Noda, "A tower model for lightning overvoltage studies based on the result of an FDTD simulation," Elect. Eng. Fapan, vol. 164, no. 1, pp. 8-20, 2008.

[27] S. Hashimoto, Y. Baba, N. Nagaoka, A. Ametani, and N. Itamoto, "An equivalent circuit of a transmission-line tower struck by lightning," 2010 30th Int. Conf. Lightning Protection, ICLP 2010, vol. 2010, pp. 2-7, 2017.

[28] H. Motoyama, Y. Kinoshita, K. Nonaka, and Y. Baba, "Experimental and analytical studies on lightning surge response of $500-\mathrm{kV}$ transmission tower," IEEE Trans. Power Del., vol. 24, no. 4, pp. 2232-2239, 2009.

[29] T. Yamada, A. Mochizuki, J. Sawada, E. Zaima, T. Kawamura, A. Ametani, M. Ishii, and S. Kato, "Experimental evaluation of a uhv tower model for lightning surge analysis," IEEE Trans. Power Deli., vol. 10, no. 1, pp. 393-402, 1995.

[30] M. Ishii, T. Kawamura, T. Kouno, E. Ohsaki, K. Shiokawa, K. Murotani, and T. Higuchi, "Multistory Transmission Tower Model For Lightning Surge Analysis," IEEE Trans. Dielectr. Electr. Insul., vol. 6, no. 3, pp. 1327-1335, 1991.

[31] M. Kawai, "Studies of the Surge Response on a Transmission Line Tower," IEEE Trans. Power App. Syst., vol. 83, no. 1, pp. 30-34, 1964.

[32] A. Ametani, K. Adachi, and T. Narita, "An Investigation of Surge Propagation Characteristics on an 1,100 kV Transmission Line," The trans. Inst. of Elect. Eng. of Japan, vol. 123, no. 4, pp. 513-519, 2003.
[33] J. L. Bermudez, J. A. Gutiérrez, W. A. Chisholm, F. Rachidi, and M. Paolone, "A Reduced-Scale Model to Evaluate the Response of Tall Towers Hit by Lightning," Int. Symp. Power Quality (SICEL), no. January, 2001.

[34] J. Takami, T. Tsuboi, K. Yamamoto, S. Okabe, and Y. Baba, "Lightning surge characteristics on inclined incoming line to substation based on reduced-scale model experiment," IEEE Trans. Dielectr. Electr. Insul., vol. 20, no. 3, pp. 739-746, 2013.

[35] D. B. Davidson, Computational electromagnetics for $R F$ and microwave engineering. Cambridge University Press, Oct. 2010.

[36] L. Grcev and F. Rachidi, "On tower impedances for transient analysis," IEEE Trans. Power Del., vol. 19, no. 3, pp. 1238-1244, 2004.

[37] J. G. Anderson, A. R. Hileman, and W. Chisholm, "A Simplified Method for Estimating Lightning Performance of Transmission Lines," IEEE Trans. Power App. and Syst., vol. PAS-104, no. 4, pp. 918-932, 1985.

[38] C. Menemenlis and Z. T. Chun, "wave propagation on nonuniform lines," IEEE Trans. Power App. Syst., vol. PAS-101, no. 4, pp. 833-839, 1982.

[39] IEEE guide for Improving the lightning performance of Transmission Lines. IEEE std. 1243-1997, Dec. 1997.

[40] C. A. Jordan, "Lightning computations for transmission lines with overhead ground wires," General Electric Rev., vol. 37, no. 4, pp. 180-186, 1934.

[41] Z. G. Datsios and P. N. Mikropoulos, "Effect of tower modelling on the minimum backflashover current of overhead transmission lines," 19th Int. Symp. on High Voltage Eng. (ISH), no. August, 2015.

[42] CIGRE WG01 SC33, "Guide to procedures for estimating the lightning performance of transmission lines, A. Eriksson (CH), L. Dellera (IT), G. Baldo (IT), C. H. Bouquegneau (BE), H. Darvenisa (AU), J. Elovaara (FI), E. Garbagnati (IT), C. Gary (FR)," Cigré Tb 63, vol. 01, no. October, p. 64, 1991.

[43] H. Motoyama, K. Shinjo, Y. Matsumoto, and N. Itamoto, "Observation and analysis of multiphase back flashover on the Okushishiku test transmission line caused by winter lightning," IEEE Trans. Power Del., vol. 13, no. 4, pp. 1391-1398, 1998.

[44] M. Ishii and Y. Baba, "Numerical electromagnetic field analysis on lightning surge response of tower with shield wire," IEEE Power Engineering Review, vol. 17, no. 1, p. 69, 2000.

[45] T. Hara, O. Yamamoto, M. Hayashi, and C. Uenosono, "Empirical formulas of surge impedance for single and multiple vertical cylinders," IEEf Trans. Power Energy, vol. 110, no. 2, pp. 129-137, 1990.

[46] G. D. Breuer, A. J. Schultz, R. H. Schlomann, and W. S. Price, "Field Studies of the Surge Response of a 345-Kv Transmission and ground wire," Trans. American Inst. Elect. Eng. Part III: Power App. Syst., vol. 76, no. 3, pp. 1392-1396, 1957.

[47] Y. Baba and M. Ishii, "Numerical electromagnetic field analysis on measuring methods of tower surge impedance," IEEE Trans. Power Del., vol. 14 , no. 2, pp. $630-635,1999$.

[48] G. J. Burke, Numerical Electromagnetic Code - (NEC-4) - Method of Moments, Part I: User's Manual, Lawrence Livermore National Laboratory.

[49] P. Yutthagowith, A. Ametani, N. Nagaoka, and Y. Baba, "Influence of a measuring system to a transient voltage on a vertical conductor," IEEF Trans. Electr. Electr. Eng., vol. 5, no. 2, pp. 221-228, 2010.

[50] J. A. Gutiérrez, P. Moreno, J. L. Naredo, and J. C. Gutiérrez, "Fast transients analysis of nonuniform transmission lines through the method of characteristics," Int. fournal Elect. Power Energy Syst., vol. 24, no. 9, pp. 781-788, 2002

[51] B. Salarieh, H. M. J. De Silva, and B. Kordi, "Wideband EMT-compatible model for grounding electrodes buried in frequency dependent soil," Int conf. Power Systems Transients (IPST2019) - Proc., 2019, Paper 19IPST081.

[52] EPRI AC transmission line reference book-200kV and above. Palo Alto, Dec. 2005.

[53] M. P. N. Datsios, Z. G. and T. E. Tsovilis, "Estimation of the minimum shielding failure flashover current for first and subsequent lightning strokes to overhead transmission lines," Electric Power Systems Research, pp. 141-150, 2014. 


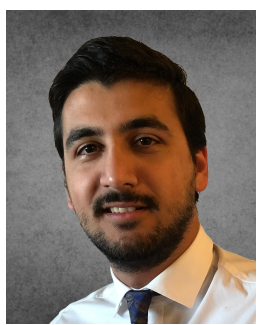

Bamdad Salarieh received the B.Sc. degree in electrical engineering from Sharif University of Technology, Tehran, Iran, and M.Sc. degree in electrical engineering from University of Manitoba, Winnipeg, MB, Canada, in 2017, and 2020 , respectively. He is currently a research engineer at Manitoba Hydro International, Winnipeg, MB, Canada. Bamdad was the recipient of the Young Scientist award at IPST 2019 conference. His research interests include Electromagnetic transients of power systems, lightning electromagnetics, and renewable energy.

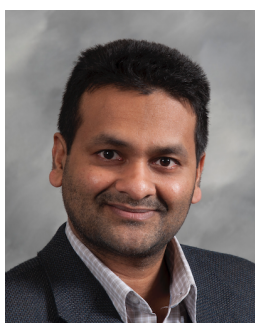

H. M. Jeewantha De Silva received B.Sc (Eng) degree at University of Moratuwa, Sri Lanka in 2001 and then Ph.D from University of Manitoba, Canada in 2009 on accurate simulation of transmission lines and cables. Dr. De Silva is a Power System Simulation and Research Engineer at the Manitoba Hydro International, Canada since 2009. He is involved with improving overhead transmission lines and cable models in PSCAD/EMTDC commercial software and also Electromagnetic Transient Program (EMT) algorithms and simulation tools. $\mathrm{He}$ is also involved in power system simulation studies and supporting PSCAD clients.

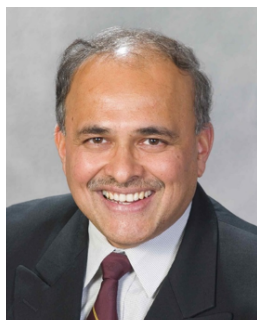

Aniruddha M. Gole (M'82, SM'04, F'10) is a Distinguished Professor and NSERC Industrial Chair in Power Systems Simulation at the Department of Electrical and Computer Engineering, University of Manitoba. He has over 30 years of experience in the development of modelling tools for power networks incorporating power-electronic equipment such as HVDC and FACTS converters. He is one of the original developers of the widely used PSCAD/ EMTDC simulation program. Dr. Gole has also made important contributions to the development of the real-time digital simulator RTDS from RTDS Technologies of Winnipeg, Canada. Dr. Gole is a Fellow of the Canadian Academy of Engineering and an IEEE Fellow. For his contributions to the modelling of Flexible AC Transmission System (FACTS) devices, he received the IEEE Nari Hingorani FACTS Award in 2007. Dr. Gole is a member of the Long Range Planning Committee of the IEEE Power and Energy Society.

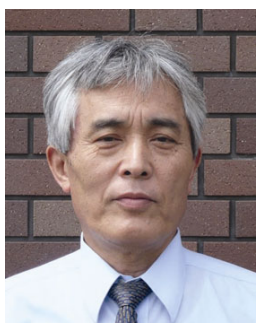

Akihiro Ametani (M'71, SM'83, F'92, LF'10) received the Ph.D. degree from UMIST, Manchester, U.K., in 1973, and the D.Sc. from the University of Manchester, Manchester, U.K., in 2010. He was with Bonneville Power Administration, Portland, OR, USA, to develop electromagnetic transients program from 1976 to 1981 . He was a professor with Doshisha University, Kyoto, Japan, until March 2014, and with Polytechnique Montrèal, Montreal, Canada, from 2014 to 2018. Currently, he is a professor with the University of Manitoba, Winnipeg, Canada. He was the Chairman of the Doshisha Council from 2011 to 2014. He served as a Vice-President of the IEE Japan in 2003 and 2004

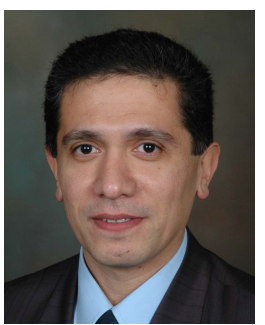

Behzad Kordi (M'05, SM'12) received the B.Sc. (with distinction), M.Sc., and Ph.D. degrees all in electrical engineering from Amirkabir University of Technology (Tehran Polytechnic), Tehran, Iran, in 1992, 1995, and 2000, respectively. During 1998 and 1999, he was with the Lightning Studies Group at the University of Toronto, Canada. In 2002, he joined the Electrical and Computer Engineering Department, University of Manitoba, Canada where he is currently a full professor and the director of McMath High Voltage Laboratory. His research interests include high voltage engineering, electromagnetic compatibility, simulation models of power transformers and transmission lines, and condition monitoring of high voltage apparatus. Dr. Kordi was the chair of URSI Canada Commission E in 2012-13. He is a member of a number of Cigrè working groups pertinent to transient modeling of power system apparatus. He is also an associate editor of IEEE Transactions on Dielectrics and Electrical Insulation and IET High Voltage. Dr. Kordi is a registered professional engineer in the province of Manitoba and was the recipient of 2012 IEEE EMC Richard B. Schulz best transactions paper award. 